\title{
LO VISIBLE Y LO INVISIBLE EN EL ROMÁNICO: FUENTES Y SIMBOLOGÍA DE LO PROFANO'.
}

\author{
The visible thing and the invisible thing in the romanesque: sources and study of \\ symbols of the profane sculpture
}

Antonio LEDESMA GONZÁLEZ

E-mail: antoniolg@usal.es

Departamento de Historia del Arte - Bellas Artes

Universidad de Salamanca

Fecha de recepción: 21-01-2010

Fecha de aceptación: 29-01-2010

\begin{abstract}
RESUMEN: Lo profano se define como "aquello que no es sagrado ni sirve a usos sagrados", sin embargo, en la cultura medieval resultará excesivamente complejo independizar mundo profano y religioso, así como el conocimiento específico de la función que desempeñan las imágenes desacralizadas, dentro de contextos estrictamente eclesiásticos. En el marco de estas interrogantes, se genera la necesidad de abordar un estudio específico sobre lo profano en la escultura románica en Salamanca, que nos permita ofrecer algunas respuestas desde nuevos enfoques metodológicos. Las investigaciones efectuadas sobre esta materia no son muy numerosas y las escasas fuentes documentales, y la pérdida de la memoria visual, junto a las transformaciones que han sufrido los templos, limitan aún más la labor a desempeñar.
\end{abstract}

Palabras Clave: románico, Salamanca, profano, simbología, metodología.

ABSTRACT: Profane is defined as "that which is not holy nor has holy usefulness", however in the medieval culture will be excessively complex to separate the profane and religious world, as well as the specific knowledge of the demystified picture role in a strictly ecclesiastic context. Due to these questions, it is generated the necessity of raising a specific study about the profane in the Romanesque sculpture in Salamanca which leads to provide some answers from new methodological approaches. The number of investigational studies performed up to now about this issue is not so high and the scarce documental fonts, lost of visual memories, along with the changes made in the temples, limit even more the task to be done.

Keywords: Romanesque, Salamanca, Profane, Symbolism, Methodology. 
Pero no sé de qué pueda servir una cantidad de monstruos ridiculos, una cierta cantidad de belleza disforme y una deformidad agradable, que se presenta sobre todas las paredes de los claustros... ¿A quéprovecho estas rústicas monas, estos leones furiosos, estos monstruosos centauros, estos semihombres, estos tigres moteados, estas gentes armadas que se combaten, esos cazadores que tocan la trompeta? San Bernardo de Claraval

\section{ESTADO DE LA CUESTIÓN}

El románico en Salamanca ${ }^{3}$, en sus múltiples manifestaciones artísticas ha sido objeto de estudio en diferentes trabajos de investigación ${ }^{4}$, extrayendo como conclusión a la hora de presentar sus particularidades que podamos hablar de románicos en lugar de un único románico, dada su pluralidad y falta de uniformidad en líneas generales, destacando si cabe la variante en ladrillo denominada habitualmente, aunque con bastantes reservas, románico-mudéjar ${ }^{5}$. Sin embargo, puede que no se haya prestado la atención suficiente al estudio y a la representación específica de la escultura profana, teniendo presente los matices que consideraremos líneas más abajo a la hora de definir este término, a diferencia de los temas puramente religiosos. En la dificultad del estudio, junto a la carencia documental específica, estriba posiblemente su poquedad investigadora. Así, exceptuando casos particulares, centrados en la escultura de la Catedral Vieja ${ }^{6}$, la serie fragmentaria de capiteles claustrales de la misma ${ }^{7}$, la portada occidental de la Iglesia de San Martín (hoy oculta por la capilla de Nuestra Señora de las Angustias $)^{8}$ y la escultura de la catedral de Ciudad Rodrigo ${ }^{9}$, no existe un trabajo que aborde de forma global e individualizada el conjunto de imágenes profanas diseminadas por los edificios románicos en Salamanca y provincia, por lo que para su desarrollo seguiremos parcialmente el planteamiento empleado por G. Boto Varela y J. L. Hernando Garrido en estudios similares al que nos proponemos realizar ${ }^{10}$.

La investigación en la que estamos inmersos se encuentra en su fase inicial y en base a esta circunstancia vamos a centrar el contenido de nuestra comunicación en los matices que tiene lo profano en la imagen medieval, método de trabajo y conclusiones previstas.

\section{INTRODUCCIÓN}

Mircea Eliade escribió que la primera definición que puede formularse sobre lo sagrado es la de su clara oposición con lo profano ${ }^{11}$, aserto que, de entrada, no deja margen para la duda, pero que no siempre se cumple como si de una ciencia exacta se tratase. En el caso particular del mundo medieval, al menos en lo que a motivos de tipo figurativo localizados en los templos se 
refiere, tanto en sus espacios internos como externos, resulta en cierto grado inverosímil dado que la religión se manifiesta por encima de cualquier otra actividad humana, hasta casi finales del medievo, como así lo confirman J.M. Nieto Soria e I. Sanz Sancho ${ }^{12}$. Sin embargo dicha afirmación debe de ser matizada, dado que la religión no es el único elemento preponderante de la vida social del hombre del medievo, aunque sí puede ser considerada como fuente reguladora de todas las demás acciones existenciales ${ }^{13}$.

Una vez realizada esta primera consideración, en base a la citada teoría de M. Eliade, partimos de la premisa de la dificultad de definir con exactitud el término profano. Según la R.A.E. profano es aquello "que no es sagrado ni sirve a usos sagrados", pero para nuestro ámbito de estudio -además de otros muchos matices- consideraremos profano únicamente aquellas representaciones que iconográficamente no sean identificadas, en un primer momento, con temas religiosos aunque a posteriori pueda variar su significado $/ \mathrm{s}^{14}$.

A grandes rasgos podemos dividir los temas profanos del románico, aún sabiendo de la imprecisión de los mismos, en tres grandes conjuntos: fitomorfos, zoomorfos y antropomorfos. El simbolismo implícito de los primeros quedó suficientemente demostrado con el estudio que desarrolló Quiñones Costa sobre el valor de la decoración vegetal en el Arte de la Alta Edad Media ${ }^{15}$, pero dado el limitado espacio de nuestro trabajo de investigación no podrá ser abordado, centrándonos exclusivamente en las dos últimas agrupaciones enumeradas.

Todas las imágenes seleccionadas para poder elaborar la investigación, forman parte de los diferentes componentes que se integran dentro de las estructuras arquitectónicas de los templos, como son capiteles, canecillos, arquivoltas, claves, enjutas, y en menor medida en ménsulas, estatuas-nervadura, además de otros componentes independientes o que, en la actualidad, aparecen descontextualizados. Deberemos de tener presente el grado de relevancia de los mismos, basándonos en su localización, contenido, calidad técnica, volumen que ocupan en los espacios, etc.

Analizaremos cada elemento figurativo de manera individualizada, aunque sin descontextualizarlos de su conjunto o agrupación, así como de su entorno histórico-social, cultural y religioso, y para ello nos serviremos de materiales fotográficos, literarios, documentales, etc., abordando el estudio del siguiente modo, aunque siempre de manera simultánea:

A) Búsqueda, recopilación y análisis de la bibliografía publicada sobre el tema en proceso de investigación. En un primer momento nos hemos centrado en la bibliografía que atañe estrictamente a las artes románicas. Yendo de lo más genérico a lo más específico, hemos iniciado el estudio con las principales obras monográficas del románico español, después castellano-leonés (aunque dicha definición no resulte acertada para el periodo histórico 
analizado), para finalizar con aquellas que tienen por objeto las construcciones salmantinas y el ambiente en el que se generan. Simultáneamente examinaremos la bibliografía correspondiente a la sociedad y religiosidad del momento histórico para poder situarnos en la mentalidad y pensamiento de los hombres de la época, así como la consulta de trabajos de carácter interdisciplinar que nos ayuden a cubrir y/o ampliar aquellos aspectos que no hayan sido tratados anteriormente.

B) El trabajo de campo ha consistido en recoger, fotografiar y ordenar, de una manera individualizada y pormenorizada, todos los elementos objeto de estudio conservados en Salamanca y provincia. A continuación, procederemos a la aplicación de los conocimientos teóricos adquiridos en el punto precedente al análisis detallado de las obras. Finalizaremos esta fase con las primeras valoraciones e interpretaciones de la información registrada.

C) Formulación de las primeras hipótesis y planteamiento de posibles respuestas a los interrogantes planteados, así como de los que puedan surgir a lo largo del estudio; confirmación o desestimación de las respuestas suscitadas al comienzo, revisión y ampliación de las mismas según avancemos la investigación y vayamos configurando una imagen más completa y precisa del objeto de estudio; búsqueda y presentación, siempre que estemos capacitados, de posibles significado/s para los diferentes elementos figurativos que aparecen en los templos; información sobre su uso y vínculo con unas fuentes concretas; comparación con obras de temática análoga identificadas y analizadas con anterioridad; finalizando con las conclusiones provisionales, aunque siempre susceptibles de variación.

El cronograma presentado está configurado para ser desarrollado a lo largo de los cuatro años de duración de la Beca de Investigación. El carácter interdisciplinar del estudio, en el que se funden cuestiones de carácter antropológico, simbólico, histórico, literario, y por supuesto artístico, será una de las características más acusadas y que dotarán al estudio de cierta individualidad.

\section{DiFICULTADES QUE PREVEMOS HALLAR}

Desde el inicio, nos enfrentamos a una serie de problemáticas de muy diversa índole a la hora de emprender la investigación sobre lo profano en la escultura monumental románica, circunstancias de carácter local que, sin embargo pueden hacerse extensibles a nivel nacional, amén de todas aquellas que nos irán surgiendo según vayamos desarrollando el estudio. Conviene precisar que bajo el término invisible recogeremos todo aquello que no es posible percibir mediante la imagen representada, por lo que deberemos de recurrir a otras fuentes para determinar su significado. 
Entre las principales dificultades podemos destacar:

1. Fuentes documentales directas no muy abundantes, siendo muy limitadas aquellas que conciernen de manera específica a los templos ${ }^{16}$. Asimismo las menciones a la escultura y su significado no se darán hasta estudios casi recientes.

2. Falta de coincidencia del marco geográfico. La actual provincia de Salamanca, basada en una organización administrativa de origen decimonónico, difiere considerablemente en su espacio geográfico de la correspondiente a los siglos XII y XIII. La ordenación, en base a las diferentes diócesis o comarcas, tampoco será elemento coincidente con la realidad del momento histórico estudiado y, por tal circunstancia, podemos encontrarnos con una fragmentación que en origen no existía ${ }^{17}$.

3. Obras de restauración. En múltiples ocasiones se ha producido una sustitución de los elementos figurativos originales, transformando así el mensaje original, sin que haya quedado constancia de las diferentes alteraciones acaecidas. En el mismo punto, incluimos construcciones inconclusas y pérdidas materiales, así como desaparición de otras manifestaciones artísticas paralelas (pintura -tanto mural como en tabla-, escultura exenta, trabajo en vidrio, arte mueble, rejería, platería, etc.) que podrían ofrecernos algún tipo de respuesta respecto a su contenido y utilidad.

4. Progresiva pérdida en la memoria colectiva, del significado de estos símbolos, de sus usos y funciones en recintos sagrados, tanto por los estamentos eclesiásticos como por la feligresía.

5. Estudios fragmentarios y carencia de obras específicas que versan sobre el simbolismo del arte románico en Salamanca y provincia. Los diferentes estudios iconográficos, cuando han sido planteados, se han desarrollado dentro de obras generales que, debido a su limitación y a la escasez de datos, no han permitido llevar a cabo la investigación con mayor profundidad. Y esto en el caso de los trabajos de investigación contemporáneos, dado que, en la gran mayoría de los estudios precedentes apenas se hace mención de aquello que en su época era considerado, de manera casi reiterativa, como simples motivos decorativos carentes de significado o de contenido desconocido ${ }^{18}$.

6. En el plano artístico, aunque resulte complejo referirnos a conceptos que son más cercanos a las mentalidades actuales, se vive durante este período un momento de transición e indefinición de las últimas formas románicas que conducen al gótico, con sus primeras manifestaciones aflorando, y esto dentro de un contexto que ya de por sí resulta retardatario con respecto a lo que se genera en otros puntos del Occidente medieval. En bastantes ocasiones, no será fácil dilucidar a qué momento exacto corresponden las labores 
efectuadas, y más si tenemos en cuenta el carácter marginal y retardatario del románico en Salamanca.

7. El número de templos que han sobrevivido hasta la actualidad es muy reducido. Solamente en la capital, de manera completa, aunque no eximidos de aditamentos posteriores, contamos con los ejemplos de la Catedral de Santa María de la Sede, Santo Tomás Cantuariense, San Cristóbal, Real Clerecía de San Marcos, San Juan de Barbalos y San Martín de Tours.

8. Pervivencia limitada únicamente a construcciones de carácter religioso aunque hay constancia de obras civiles (ejemplo de esto serían las viviendas palaciegas de Raimundo y Urraca o la residencia del Concejo, aunque al no contar con fuentes que certifiquen su aparición no es posible asegurar la existencia de formas figurativas en los mismos).

\section{Metodología}

Para solventar estas múltiples circunstancias adversas, pretendemos abordar el trabajo desde diferentes enfoques pero siendo todos regidos bajo un mismo hilo conductor:

1. Dado que apenas contamos con fuentes originales que traten sobre el contenido simbólico de las obras esculpidas, realizaremos una consulta lo más amplia posible- de fuentes escritas indirectas, como son los textos de carácter normativo (Fuero de Salamanca), literatura profana (refraneros castellanos o cantares de gesta), textos canónicos (Sagradas Escrituras), apócrifos (Leyenda Dorada), sermonarios, etc., y de fuentes más modernas, como son las diferentes Historias de Salamanca y otros estudios multidisciplinares, vinculados con nuestra investigación. Así, gracias a la Crónica del Pseudo Tur$\operatorname{pin}^{19}$ y otras fuentes literarias narrativas, se ha podido identificar en un capitel del pilar toral del transepto de la Catedral de Santa María de la Sede de Salamanca, la más que probable representación del combate entre Roldán y Ferragut ${ }^{20}$. Sin embargo, deberemos de tener presente la afirmación de Boto Varela, el cual considera "ineficaz recurrir a la hermenéutica textual para esclarecer las intenciones de los responsables" como único medio de descifrar su significado ${ }^{21}$.

2. Limitación a un área geográfica específica en base a criterios de radiación de focos y/o templos destacados, y que presentan cierta vinculación entre sí.

3. Revisión y consulta de archivos y fuentes documentales que puedan albergar algún tipo de información sobre las transformaciones habidas en los diferentes templos analizados, así como de fuentes visuales como foto- 
grafías o dibujos históricos que nos informen sobre la misma cuestión. De este modo, por medio de una fotografía realizada en 1927 y localizada en el Archivo Mas de Barcelona, tenemos constancia de la alteración material, que no iconográfica, que sufrió una de las esculturas-nervio, correspondiente a San Miguel alanceando al dragón, de la Catedral Vieja de Salamanca ${ }^{22}$.

4. Modelos de épocas precedentes que nos permitan ofrecer algún tipo de respuesta a las representaciones posteriores y que aún sirviéndose de diferente estética y significado, se siguen generando a lo largo del tiempo. Aunque son escasos los ejemplos tal opción no puede ser descartada. El caso más paradigmático al respecto es el de la reproducción del sarcófago romano de Husillos en uno de los capiteles de la iglesia de San Martín de Frómista, con la representación de la Orestíada ${ }^{23}$.

\section{OBJETIVOS PREVISTOS}

Los principales objetivos que pretendemos alcanzar se resumen en:

- Presentación de un corpus específico sobre lo profano, con los matices que sean pertinentes, para el caso del románico en Salamanca y provincia.

- Recopilación y ordenación del material gráfico existente, evaluando su interés y relevancia dentro del ámbito de la escultura románica analizada.

- Distinción entre piezas primigenias y transformaciones ulteriores sufridas en los templos a lo largo de su existencia o, al menos, desde que se tenga evidencias documentales que así lo confirmen.

- Desciframiento del lenguaje expresado por medio de los elementos narrativos, significado/s conforme a la realidad del momento y función que desempeñan dentro de contextos exclusivamente religiosos.

- Establecer el grado de diferenciación, en caso de producirse, entre las formas desligadas de lo sagrado de las vinculadas expresamente con lo religioso.

- Confirmación de la existencia de programas unificados o representaciones aisladas inconexas aunque conformando micro-agrupaciones.

- Grado de relevancia de las diferentes agrupaciones profanas que se pueden constituir en cada templo, dando un cómputo final de los mismos y ofreciendo una lectura crítica de los resultados obtenidos ${ }^{24}$.

- Identificación y/o vinculación con las posibles fuentes primigenias, en el caso de que existan y sean localizadas, que permitan analizar con mayor exactitud las obras seleccionadas. 
Los datos finales a los que nos puede conducir esta investigación, no eximidos de revisiones posteriores, podrán servir para un conocimiento más preciso sobre el románico en Salamanca y provincia.

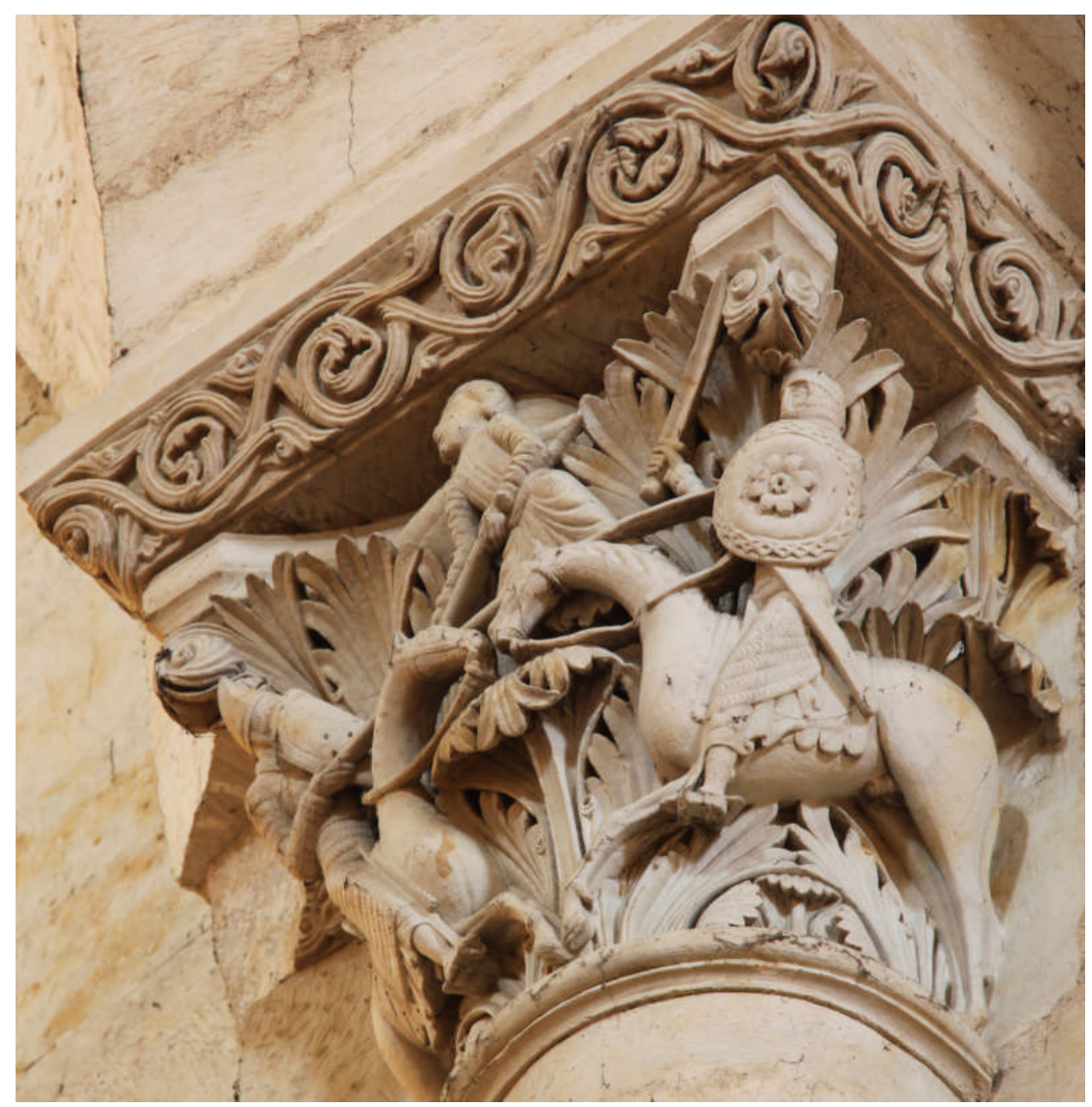

I - Catedral Vieja de Salamanca. Capitel en el pilar toral del transepto. 


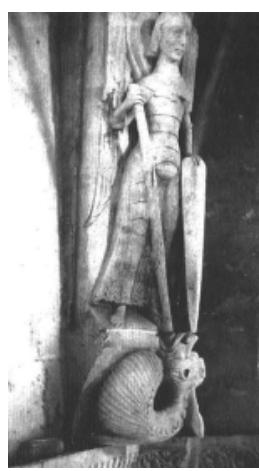

IIa - Catedral Vieja de Salamanca.

Brazo meridional del crucero. San Miguel en 1927.

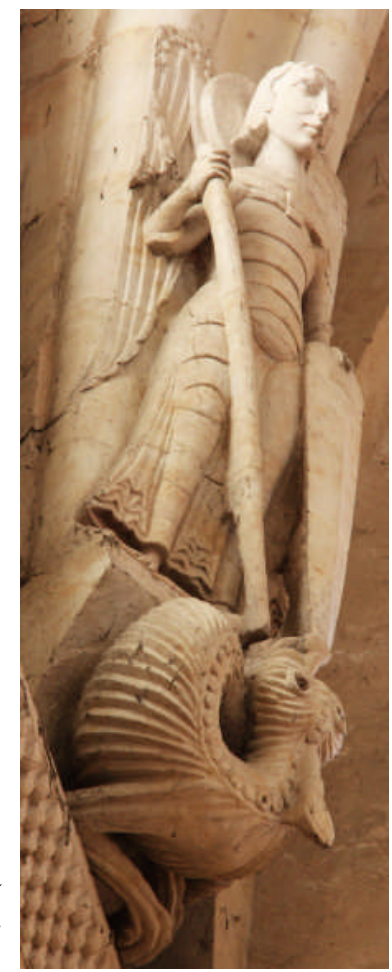

II b (derecha de II a) - San Miguel en la actualidad.

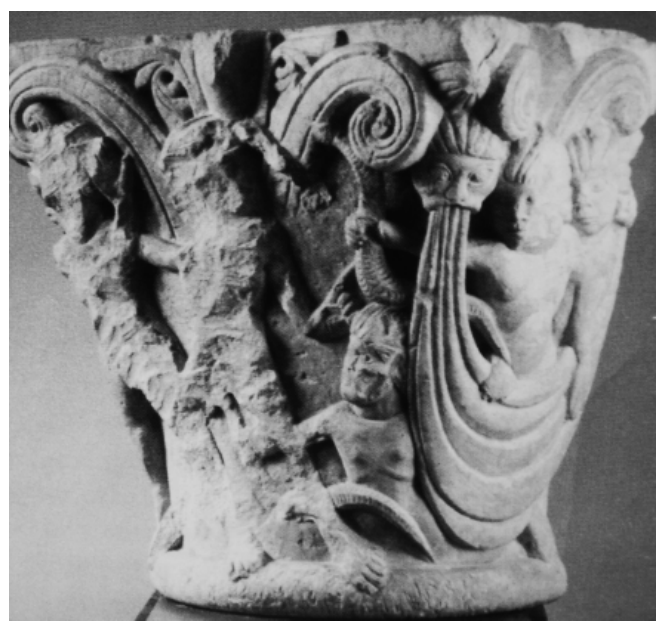

IIIa - Capitel de la iglesia de San Martin de Fromista (Palencia). Actualmente en el Museo de Palencia. 


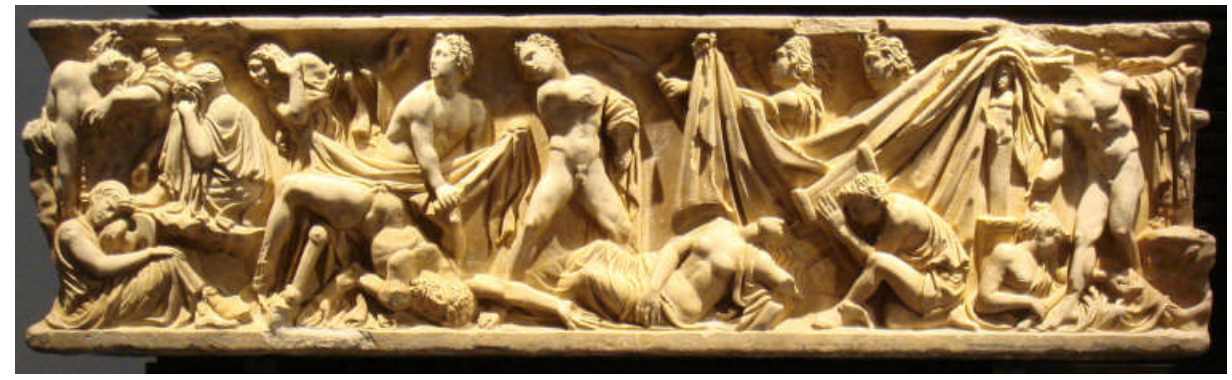

IIIb - Sarcofago romano de Husillos.

Museo Arqueológico Nacional de Madrid.

\section{Notas}

${ }^{1}$ El siguiente texto se enmarca dentro del trabajo de investigación titulado "Lo profano en el románico castellano-leonés”, financiado por la Consejería de Educación y el Fondo Social Europeo, y desarrollado en la Universidad de Salamanca, Departamento de Historia del Arte-Bellas Artes, bajo la dirección de Manuel Pérez Hernández.

${ }^{2}$ SAN BERNARDO DE CLARAVAL. Obras completas de San Bernardo. Vol. 2. Madrid: Editorial Católica, 1955. Apología a Guillermo, abad de Saint-Thierry, p. 849-850.

${ }^{3}$ Martínez Frías en su estudio sobre el románico de la ciudad de Salamanca pone en evidencia que "no se puede determinar con carácter absoluto un "románico salmantino", pues apenas sí existen en sus edificios rasgos con la suficiente fuerza de originalidad como para crear un foco de características independientes y distintivas, aunque a no dudar muestren una acentuada homogeneidad”. MARTÍNEZ FRÍAS, J. M. El arte románico en Salamanca. [Salamanca]: La Gaceta, D.L. 2004. p. 42.

${ }^{4}$ GÓMEZ-MORENO, M. Catálogo monumental de España. Provincia de Salamanca. [Madrid]: Servicio Nacional de Información Artística, imp. 1967. PRADELIER, H. La sculpture monumentale à la Catedral Vieja de Salamanque. Tesis inédita. Universidad de Toulouse-le-Mirail, 1978. PRIETO PANIAGUA, M. R. La arquitectura románico-mudéjar en la provincia de Salamanca. Salamanca: Centro de Estudios Salmantinos, Consejo Superior de Investigaciones Científicas, 1980. MARTÍNEZ FRÍAS, J. M. en CABO ALONSO, Á., ORTEGA CARMONA, A. (coordinadores). Salamanca: geografía, historia, arte, cultura. Salamanca: Ayuntamiento de Salamanca, Servicio de Publicaciones, 1986. p. 317-339. RUIZ MALDONADO, M. El caballero en la escultura románica de Castilla y León. Salamanca: Ediciones Universidad de Salamanca, 1986. VI- 
ÑAYO GONZÁLEZ, A. León y Asturias: Oviedo, León, Zamora y Salamanca. Madrid: Encuentro, 1987. p. 353-400. Fotografía de: Zodiaque. ENRÍQUEZ DE SALAMANCA, C. Rutas del románico en la provincia de Salamanca. Las Rozas (Madrid): Cayetano Enríquez de Salamanca; Salamanca: Librería Cervantes, 1989. RUIZ MALDONADO, M. La iglesia románica de Almenara de Tormes. Salamanca: Ediciones Universidad de Salamanca, 1989. BANGO TORVISO, I. G. El arte románico en Castilla y León. Madrid: Banco de Santander, 1997. p. 179-207. NIETO GONZÁLEZ, J. R. Ciudad Rodrigo: análisis del patrimonio artístico. Salamanca: Durius Cultural, 1998. RUIZ MALDONADO, M. Faciamus hominem ad imaginem... La figura humana en la escultura monumental de la Catedral Vieja de Salamanca en La cabecera de la catedral calceatense y el Tardorrománico hispano. [Santo Domingo de la Calzada]: Cabildo de la S.M.I., Catedral de Santo Domingo de la Calzada, [2000]. p. 328. MARTÍNEZ FRÍAS, J. M. La Catedral Vieja y las iglesias románicas en BENET, N. [et al.]. Salamanca: ciudad europea de la cultura 2002. Salamanca: Caja Duero, D.L. 2001. p. 83-122. GARCÍA GUINEA, M. A., PÉREZ GONÁLEZ, J. M. dirección. Enciclopedia del Románico en Castilla y León. Salamanca. Aguilar de Campoo: Fundación Santa María La Real, Centro de Estudios del Románico, 2002. t. 1. ÁLVAREZ VILLAR, J. La iglesia románica de San Marcos de Salamanca. Salamanca: Caja Duero, 2004. MARTÍNEZ FRÍAS, J. M. El arte románico en Salamanca. [Salamanca]: La Gaceta, D.L. 2004.

${ }^{5}$ Sobre los debates generados en torno al término mudéjar véase: RUZAFA GARCÍA, M. G. En torno al término "mudéjar": concepto y realidad de una exclusión social y cultural en la Baja Edad Media en Mudéjares y moriscos, cambios sociales y culturales: Actas [del] Simposio Internacional de Mudejarismo, Teruel, 12-14 de septiembre de 2002. Teruel: Centro de Estudios Mudéjares, Instituto de Estudios Turolenses, 2004. p. 19-26. BORRÁS GUALIS, G. M. Consideraciones para una definición cultural del arte mudéjar en Simposio Internacional "El legado de Al-Andalus. El arte andalusí en los reinos de León y Castilla durante la Edad Media". Valladolid: Fundación del Patrimonio Histórico de Castilla y León, 2007. p. 409-424.

${ }^{6}$ PRADELIER, H. La sculpture monumentale à la Catedral Vieja de Salamanque. Tesis inédita. Universidad de Toulouse-le-Mirail, 1978.

${ }^{7}$ HERNANDO GARRIDO, J. L. La escultura románica en el claustro de la catedral de Salamanca. Locus amoenus. $1998, \mathrm{n}^{\circ}$ 4, p. 59-75.

${ }^{8}$ RUIZ MALDONADO, M. La puerta occidental de la iglesia de San Martín. Boletín del Seminario de Estudios de Arte y Arqueología: BS AA. 1985, no 51, p. 446-450.

${ }^{9}$ MARTÍNEZ FRÍAS, J. M. La configuración arquitectónica de la catedral de Ciudad Rodrigo a lo largo del medievo en AZOFRA AGUSTÍN, E. (editor) La Catedral de Ciudad Rodrigo a través de los siglos: visiones y revisiones. [Salamanca]: Diputación de Salamanca: Caja Duero Obra Social: Diócesis de Ciudad Rodrigo, D. L. 2006, p. 109-158. LAHOZ GUTIÉRREZ, M. L. Sobre galerías, portadas e imágenes: la escultura monumental en la catedral de Ciudad Rodrigo en AZOFRA AGUSTÍN, E. (editor) La Catedral de Ciudad Rodrigo a través de los siglos: visiones y revisiones. [Salamanca]: Diputación de Salamanca: Caja Duero Obra Social: Diócesis de Ciudad Rodrigo, D. L. 2006, p. 195-252.

${ }^{10} \mathrm{Trabajos}$ referenciales son: HERNANDO GARRIDO, J. L. Escultura tardorrománica en el 
Monasterio de Santa María La Real en Aguilar de Campoo (Palencia). Aguilar de Campoo (Palencia): Fundación Santa María La Real, Centro de Estudios del Románico, D.L. 1995. BOTO VARELA, G. Ornamento sin delito: los seres imaginarios del Claustro de Silos y sus ecos en la escultura románica peninsular. Santo Domingo de Silos (Burgos): Abadía de Silos, 2000. También resultará de interés el estudio: HERRERO MARCOS, J. Arquitectura y simbolismo del románico de Cantabria. [Madrid]: Ars Magna, 1996.

${ }^{11}$ ELIADE, Mircea. Lo sagrado y lo profano. Barcelona: Labor, 1992. p. 18. Traducción de: Luis Gil.

${ }^{12}$ NIETO SORIA, J. M, SANZ SANCHO, I. La época medieval: iglesia y cultura. Tres Cantos (Madrid): Istmo, cop. 2000. Del mismo modo Fernando Díaz-Plaja afirmará que "la religión informa toda la vida del país, y sus reglas son obedecidas por todos". DÍAZ-PLAJA, F. La vida cotidiana en la España medieval. Madrid: Edaf, D.L. 1995. p. 24.

${ }^{13}$ En el artículo “La violencia convertida en espectáculo”, Víctor M. Gibello Bravo describe cómo en los torneos y justas participaban la inmensa mayoría de los miembros de la aristocracia del momento, pero que aún así eran condenadas por la Iglesia (Concilio de Clermont, 1130) incluso cuando muchos de los valores que enarbolaban coincidían con los del propio cristianismo. GIBELLO BRAVO, V. M. La violencia convertida en espectáculo: Las fiestas caballerescas medievales. Fiestas, juegos y espectáculos en la España Medieval: actas del VII Curso de Cultura Medieval celebrado en Aguilar de Campoo (Palencia) del 18 al 21 de Septiembre de 1995. Madrid: Fundación Sta. María La Real, 1999, p. 160. Del mismo modo en "Las fiestas juglarescas en la España Medieval", Carlos Cid Priego indica sobre los juglares que, aunque condenados públicamente por el estamento religioso, eran consentidos en la sociedad en casi todos los ámbitos. CID PRIEGO, C. Las fiestas juglarescas en la España Medieval: Sus representaciones artísticas. Fiestas, juegos y espectáculos en la España Medieval: actas del VII Curso de Cultura Medieval celebrado en Aguilar de Campoo (Palencia) del 18 al 21 de Septiembre de 1995. Madrid: Fundación Sta. María La Real, 1999, p. 96-97. Ambos ejemplos ponen en evidencia el peso de lo religioso en todas las actividades de la sociedad, incluidas las lúdicas.

${ }^{14}$ Gómez Moreno describe uno de los capiteles de la galería meridional del claustro de la Catedral Vieja, penúltimo arcosolio, e informa que está constituido por dragones cuyo pescuezo abraza una mujer. GÓMEZ-MORENO, M. Catálogo monumental de España. Provincia de Salamanca. [Madrid]: Servicio Nacional de Información Artística, imp. 1967. p. 114. En cambio, José Luis Hernando Garrido afirmará años después sobre el mismo capitel, basándose en diferentes aportaciones, que se trata de la Ascensión de Alejandro. HERNANDO GARRIDO, J. L. La escultura románica en el claustro de la catedral de Salamanca. Locus amoenus. $1998, \mathrm{n}^{\circ}$ 4, p. 71.

${ }^{15}$ QUIÑONES COSTA, A. M. La decoración vegetal en el Arte Español de la Alta Edad Media: su simbolismo. Publicación Madrid: Universidad Complutense de Madrid, Servicio de Publicaciones, [2002]. Recurso electrónico.

${ }^{16}$ Mínguez Fernández en su estudio introductorio sobre la repoblación de los territorios salmantinos hace constar que: "La elaboración de la historia de Salamanca durante la larga etapa que va de comienzos del siglo VIII -fecha de la invasión musulmana- hasta finales del 
siglo XI -repoblación definitiva de Alfonso VI- se enfrenta a un obstáculo poco menos que insalvable: la inexistencia prácticamente total de fuentes". MARTÍN, J. L. (director). Historia de Salamanca. Salamanca: Centro de Estudios Salmantinos, 1997-2001. p. 15-16. Para fechas posteriores González García considera que: "la documentación y las obras históricas sobre Salamanca no presentan datos suficientes para rehacer la vida de los salmantinos en la Baja Edad Media en su totalidad”. GONZÁLEZ GARCÍA, M. Salamanca: la repoblación y la ciudad en la Baja Edad Media. Salamanca: Centro de Estudios Salmantinos, 1988. p. 10.

17 “Conviene precisar desde el primer momento que el territorio de la actual provincia de Salamanca no tiene prácticamente ningún equivalente seis, ocho o diez siglos atrás". MARTÍN, J. L. (director). Historia de Salamanca. Salamanca: Centro de Estudios Salmantinos, 19972001. p. 11.

${ }^{18}$ Antonio Ponz, refiriéndose a la catedral de Santa María de la Sede, escribe que "los ornatos de sus sepulcros antiguos, colocados por las paredes, y los demás de la arquitectura son extraños...”. PONZ, A. Viaje de España. V. 3 (t. IX-XIII). Madrid: Aguilar, D.L. 1969. p. 645. De igual modo Gil González Dávila, refiriéndose a la misma construcción, indica que "en cada una de las superficies de los pilares sus columnas redondas, con basas y capiteles, adornados de varios labores". GONZÁLEZ DÁVILA, G. Historia de las antigüedades de la ciudad de Salamanca. Estudio introductorio y notas: Baltasar Cuart Moner. Salamanca: Ediciones Universidad de Salamanca: Ediciones Diputación de Salamanca, 1994. p. 85.

${ }^{19}$ Liber Sancti Jacobi “Codex Calixtinus”. Traducción de A. Moralejo, C. Torres y J. Feo. [Santiago de Compostela]: Xunta de Galicia, Consellería de Cultura, Comunicación Social e Turismo, D.L. 1998.

${ }^{20}$ GARCÍA GUINEA, M. A., PÉREZ GONÁLEZ, J. M. (dirección). Enciclopedia del Románico en Castilla y León. T. 1. Salamanca. Aguilar de Campoo: Fundación Santa María La Real, Centro de Estudios del Románico, 2002. Estudio introductorio de Margarita Ruiz Maldonado: Peculiaridades del románico en Salamanca. p. 57-58. Una información más amplia y detallada respecto a la figura del caballero en la escultura medieval: RUIZ MALDONADO, M. El caballero en la escultura románica de Castilla y León. Salamanca: Ediciones Universidad de Salamanca, 1986.

${ }^{21}$ BOTO VARELA, G. Ornamento sin delito: los seres imaginarios del Claustro de Silos y sus ecos en la escultura románica peninsular. Santo Domingo de Silos (Burgos): Abadía de Silos, 2000. p. 40.

${ }^{22}$ RUIZ MALDONADO, M. Faciamus hominem ad imaginem... La figura humana en la escultura monumental de la Catedral Vieja de Salamanca en La cabecera de la catedral calceatense y el Tardorrománico hispano. [Santo Domingo de la Calzada]: Cabildo de la S.M.I., Catedral de Santo Domingo de la Calzada, [2000]. p. 328.

${ }^{23}$ MORALEJO, S. Capitel inspirado en un sarcófago con escenas de la Orestiada en Santiago, Camino de Europa. Culto y cultura en la peregrinación a Compostela. [Santiago de Compostela]: Xunta de Galicia, Dirección Xeral do patrimonio Histórico e Documental, 1993. p. 373376. 
${ }^{24}$ FLOUD, R. Métodos cuantitativos para historiadores. Versión española de Jaime García-Lom-

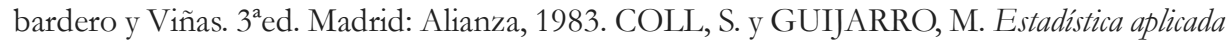
a la bistoria y a las ciencias sociales. Madrid: Pirámide, D.L. 1998. 